condition may also occur in association with streptococcal cellulitis. ${ }^{4}$ This sequence was initially suspected in one of our patients (case1) but subsequently this patient was shown to have sarcoidosis. There is no evidence that antibiotics have an adverse effect on the course of erythema nodosum.

The skin lesions of erythema nodosum are often preceded or accompanied by fever, malaise, and arthralgia. These symptoms are a feature of the underlying condition, and erythema nodosum may be considered a skin marker of the process. Joint manifestations occur in $75 \%$ of cases, with arthralgia being more common than synovitis. The synovitis is self limiting and non-erosive and symmetrically affects the knees and ankles and less commonly the wrists, elbows, small joints of the hands, and shoulders in one third of patients with erythema nodosum. The affected joints are painful, stiff and tender, and an effusion is usually present.

There may be difficulty when the condition presents before a classical pattern has evolved. Erythema nodosum has previously been reported as being misdiagnosed as cellulitis ${ }^{2}$ and soft tissue sarcoma. ${ }^{7}$ Any tender, red nodule, especially on the shin, should be carefully examined and a search made for lesions on the other side and on other typical areas. The diagnosis should also be considered in patients with arthralgia and synovitis, especially if affecting typical joints. If erythema nodosum is strongly suspected, the patient should have a chest $x$ ray and should be referred to the medical service at the time of presentation for further management. However, if a classical pattern is not recognised, it would be useful to review the patient again in the $A \& E$ department in two or three days, at which time more classical features may have evolved. The patient should be advised to return to the $A \& E$ department in the interim should the skin lesions progress. It may be necessary to treat the condition as a cellulitis until features of erythema nodosum are recognised.

$1 \mathrm{O}^{\prime}$ Neill JH. The differential diagnosis of erythema nodosum. Delaware Med f 1991;63:683-9.

2 Hebel JL, Snider RL, Mitchell D. Lofgren's syndrome. Cutis 1993;52:223-4.

3 Green GA, Maltz BA. Case report: bilateral ankle sprain in an aerobic dancer. Med Sci Sport Exerc 1992;24:1316-20.

Ryan TJ. Diseases of the skin. In: Weatherall DJ, Ledingham JGG, Warren DA, eds. Oxford textbook of medicine, 2 nd ed. Oxford: Oxford University Press, 1987:16.55, 20.66, 20.67

5 Sauer GC. Manual of skin diseases, 5 th ed. Philadelphia: JB Lippincott Co, 1985:112.

6 Atanes A, Gomez N, Aspe B, de Toro J, Grana J, Sanchez JM, et al. Erythema nodosum: a study of 160 cases. Med JM, et al. Erythema nod.
Clin 1991;96:169-72.

7 Siriwardena AK. Erythema nodosum minicking soft tissue sarcoma. Br f Clin Pract 1990;44:515.

\title{
A confused drug addict: the importance of considering sepsis
}

\author{
P Cornelius, E Pourgourides, S Meek
}

\begin{abstract}
The case is reported of a 35 year old heroin addict presenting with acute confusion which was later found to be due to meningococcal meningitis. Other than his altered mental state, the only abnormal finding on examination was a mild pyrexia. ( A Accid Emerg Med 1996;13:212-213)
\end{abstract}

Key terms: sepsis; heroin addiction; acute confusion

\section{Case report}

A 35 year old male who is a registered heroin addict was brought by ambulance to the accident and emergency (A\&E) department at $11 \mathrm{pm}$, accompanied by his girlfriend, who had found him in an aggressive and confused state. He was on a methadone replacement programme and had taken his normal dose of methadone in the morning, together with a small dose of intravenous heroin. He subsequently went to college and returned at midday complaining of a mild headache. His girlfriend then left him alone and returned in the evening to find that the room had been smashed up and the patient was acutely disturbed, violent, and aggressive.

On examination in the $A \& E$ department, he was alert but disorientated in both time and space and was aggressive and uncooperative. General physical examination was unremarkable apart from the presence of a mild pyrexia of $37.5^{\circ} \mathrm{C}$; there was no focal neurological deficit, no neck stiffness, and no rash. Venepuncture was difficult because of his intravenous drug abuse and aggressive state. Eventually a small sample was obtained which was sent for a full blood count. This showed a haemoglobin concentration of $16.4 \mathrm{~g} /$ litre and a white count of $28.8 \times 10^{9} /$ litre, with $89 \%$ neutrophils. A diagnosis of toxic confusional state secondary to infection was made and he was admitted for further investigation, including computerised tomography brain scan and lumbar puncture. Because of continued agitation he required sedation and ventilation. Neisseria meningitidis was subsequently grown from his blood cultures and CSF samples. Tests for HIV were negative. His inpatient stay was protracted and complicated by broncho- 
pneumonia and rhabdomyolysis and he was discharged after three weeks.

\section{Discussion}

This case illustrates some of the problems faced in the $A \& E$ department with the management of the confused uncooperative patient. A good history is not always available and full examination, in particular neurological assessment, may be very difficult. Even simple investigations present practical difficulties. In this case venepuncture presented additional difficulties because of the patient's intravenous drug abuse, and for further investigations he had to be sedated.

It is well recognised that "drunk" patients with head injuries are difficult to assess. This case shows that equal care must be taken when assessing the drug addict with confusion. The confusion must not be attributed to the effects of drugs until a full differential diagnoses has been considered. This must include infection, metabolic causes, subarachnoid haemorrhage, and head injury. Other than his altered mental status, the only abnormal examination finding was mild pyrexia. Any degree of pyrexia in the confused patient should be regarded as an absolute indication for urgent investigation, regardless of the difficulties associated with venepuncture and other procedures.
Meningococcal infection has a mortality of up to $24 \%$, ${ }^{1}$ which is increased if there is diagnostic or therapeutic delay. In $10 \%$ of cases the presentation is predominantly of septicaemia, with no clinical features of meningeal involvement. A purpuric or petechial rash may be present in only $52 \%$ of cases. ${ }^{2}$ In our patient, the diagnosis could easily have been missed, with disastrous consequences.

Intravenous drug abusers are at increased risk of infections. This is a result of a combination of factors, which include needle contamination, poor hygiene, and HIV infection. The most common infections requiring admission are cutaneous, respiratory, and endocardial, ${ }^{3}$ with streptococci and staphylococci being the most commonly isolated pathogens. ${ }^{4}$

There is no evidence for an association between intravenous drug abuse and meningococcal infection.

1 Strang JR, Pugh EJ. Meningococcal infections: reducing the case fatality by giving penicillin before admission to case fatality by giving penicilin
hospital. BMF 1992;305:141-3.

2 Cartwright K, Reilly S, White D, Stuart J. Early treatment with parenteral penicillin in meningococcal disease. $B M \mathcal{J}$ with parenteral penic

3 Beaufoy A. Infections in intravenous drug users: a two year review. Can f Infect Control 1993;8:7-9.

4 Weisse AB, Heller DR, Schimenti RJ, Montgomery RL, Kapila $R$. The febrile parenteral drug user, a prospective study in 121 patients. Am $\mathcal{F}$ Med 1993;94:274-80.

\title{
Perilunate fracture-dislocation: a continually missed injury
}

\author{
D H Sochart, P D Birdsall, A S Paul
}

\begin{abstract}
Five cases of perilunate fracturedislocation are presented in which the radiological appearances were typical but the diagnoses were initially missed. A simple systematic method of $x$ ray analysis is described.

(f Accid Emerg Med 1996;13:213-216)
\end{abstract}

Key terms: perilunate dislocation; missed diagnosis; $x$ ray interpretation

Department of

Orthopaedics, Bury General Hospital, Bury, Manchester

D H Sochart

Department of Orthopaedics, North

Tees Hospital

P D Birdsall

Department of Orthopaedics, Manchester Royal Infirmary, Manchester A S Paul

Correspondence to: Mr D H Sochart,

7 Woodlea, Walkden Road, Worsley, Manchester M28 2QJ, United Kingdom. instability. We present five cases in which the radiological appearances were typical but the diagnoses were initially missed and describe a simple systematic method of $x$ ray analysis to avoid future misinterpretation.

\section{Case reports}

CASE 1

A 32 year old left handed mechanic fell from his motorbike while returning from holiday in Holland. He sustained a hyperextension injury to his left wrist and attended the local hospital where $x$ rays were taken and he was told that he simply had a "chipped bone". He was supplied with a sling but during the crosschannel journey home his hand became increasingly painful and he developed numbness in his left thumb, index, and middle fingers. Following disembarkation he attended the nearest $A \& E$ department but again received the same instructions. On his return home he attended his local A\&E department, now 48 hours from the time of the injury. His wrist was very swollen and painful and he had loss of sensation in the median nerve distribution. Review of the initial $x$ rays (fig 1 ) showed obvious trans-styloid perilunate dislocation, and he was managed by open reduction and $\mathrm{K}$-wire stabilisation through a volar approach, to allow decompression of the 